\title{
Analysis of Noise Pollution in Kolhapur City and Technical Remedy to Reduce Noise Level
}

\author{
Mr. Gaurav Sanjay Patil \\ M.Tech Environmental Science \& Technology \\ Department of Technology, Shivaji University \\ Kolhapur, India
}

\author{
Dr. G. S. Kulkarni \\ Deputy Registrar (Civil) \\ Shivaji University \\ Kolhapur, India
}

\begin{abstract}
Noise Contamination is a significant viewpoint other than Air and Water contamination since it influences mental and physical wellbeing just as obstruction with records of human solace and feelings, for example, impact on rest, discussion, recurrence of instigated condition of irritation, hearing misfortune, cardiovascular issue, just as consistent attitude to help assignments execution (Singh\&Davar 2004).

Accordingly commotion contamination has become to be not kidding issue, thus "The Noise Pollution (Regulation and Control) Rules, 2000" have additionally been executed by Administration of India in the ongoing past for guideline and control of noise delivering and producing sources.

Kolhapur is Notable and vacationer place. Loads of lovers and visitors visits city consistently, additionally industrialization has developed in city in huge sum which has caused expanded number of vehicles.

Expanded vehicles, populace has caused expanded noise level of Kolhapur. This undertaking will incorporate the investigation of noise level of different focuses at different time and different conditions in Kolhapur and Specialized measures to control Commotion Level.
\end{abstract}

Keywords - Contamination, physical wellbeing, cardiovascular issue.

\section{INTRODUCTION}

\subsection{General aspects of noise pollution}

Sound that is unacceptable or disturbs one's personal satisfaction is called as noise. Right when there is a great deal of commotion in nature past certain farthest point, it is named as noise pollution. Sound ends up bothersome when it exasperates the ordinary exercises, for example, working, resting, and during discussions. It is a misjudged natural issue as a result of the way that it can't be seen, smelt, or tasted. World Wellbeing Association (Report 2001) expressed that "Noise must be perceived as a noteworthy risk to human prosperity" Noise is regularly characterized as 'undesirable sound'. An increasingly exact definition could be: commotion is capable of being heard sound that causes aggravation, weakness or wellbeing harm. The terms 'commotion' and 'sound' are frequently synonymously utilized when simply acoustical measurement is implied (e.g., noise level, noise pointer, noise guideline, commotion limit, commotion standard, commotion activity plan, air ship commotion, street traffic noise, word related noise, and so on.). The connection among introduction and result (different terms: endpoint, response, reaction) is given by sensibly entrenched presentation reaction. Overseeing noise is pivotal for upgrading the living state of an abode. Noise can be created inside a structure (e.g., commotion from encompassing neighbors' voices, music or apparatuses) or remotely (e.g., traffic noise from autos, transports, Rail way, airplane, mechanical exercises or encompassing development exercises). Commotions are passed from body of structure member from noise origin, for example, motors or pedestrian activity, slamming, or articles falling on to the floor and can likewise be related with vibrations.

Table No. 1 noise Standards (CPCB):-

\begin{tabular}{|c|c|c|}
\hline \multirow{2}{*}{ Location } & \multicolumn{2}{|c|}{ Limit } \\
\cline { 2 - 3 } & Day & Night \\
\hline Residential & 55 & 45 \\
\hline Industrial & 75 & 70 \\
\hline Silence Zone & 50 & 40 \\
\hline Commercial & 65 & 55 \\
\hline
\end{tabular}

Environmental (Protection) Act.

Note:

- Day -6 a.m. to 10 p.m.

- Night -10 p.m. to 6 a.m.

- Silence zone is eluded as territories up to 100 meters around such.

- Premises as emergency clinic, instructive organizations and courts.

- The quietness zones are to be announced by the Capable Specialist.

- Use of vehicular horns, amplifiers and blasting of saltines will be restricted in these zones

\section{OBJECTIVE}

1. To measure the noise level of various locations in Kolhapur City.

2. To measure temperature of same locations.

3. To evaluate and the number of vehicles and their contribution to noise pollution.

4. To study acoustic materials

5. To suggest measures in order to control noise level.

\section{MetDOLGY}

1. In this study comparison will be made of the noise level in main areas of Kolhapur city during the morning hour and evening hour traffic using sound level meter. Atmospheric conditions like temperature will also be recorded. 
2. The time for taking reading will be $9.00 \mathrm{AM}$ to 11.00 $\mathrm{AM}$ and 4.00 PM to 6.00PM.

3. The comparison of noise data will be plotted in form of chat for convenience.

4. Various acoustic materials will be studied and best suitable will be used to control noise level.

Kolhapur city is situated on the bank of perennial river Panchaganga. Kolhapur is one of the major fast growing urban centers in Maharashtra state. Kolhapur city has $5,49,283$ population.

\begin{tabular}{|c|c|c|c|}
\hline Sr. & Name of Site & Latitude & Longitude \\
\hline 1 & CSIBER square & $16^{0} 41^{\prime} 16.08^{\prime \prime} \mathrm{N}$ & $74^{0} 15^{\prime} 7.56^{\prime} \mathrm{E}$ \\
\hline 3 & Dabholkar Corner & $16^{0} 42^{\prime} 15.233^{\prime \prime} \mathrm{N}$ & $74^{0} 15^{\prime} 30.088^{\prime} \mathrm{E}$ \\
\hline 4 & Kolhapur Airport & $16^{0} 39^{\prime} 54.72{ }^{\prime} \mathrm{N}$ & $74^{0} 16^{\prime} 58.088^{\prime} \mathrm{E}$ \\
\hline
\end{tabular}
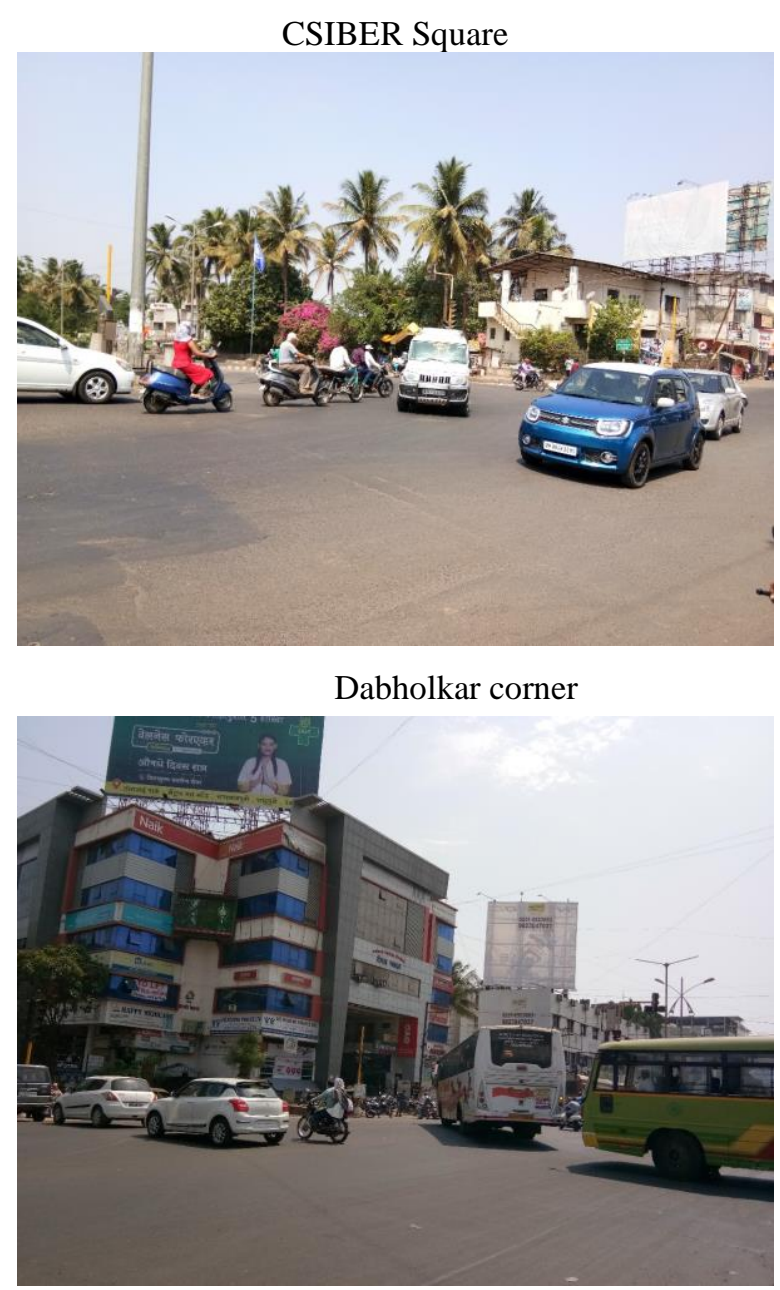

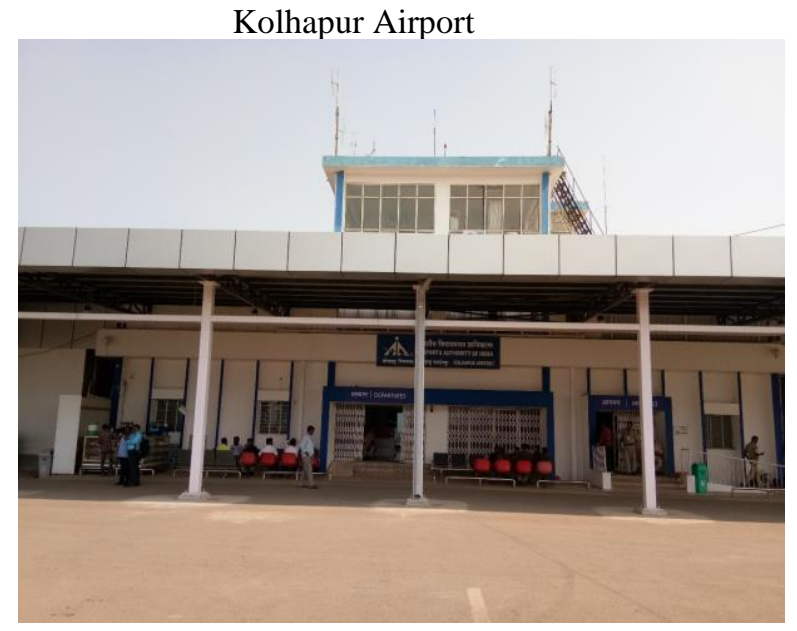

\section{THEORY AND CONCEPT}

\subsection{Sound Absorbing Materials and Their Use}

Sound engrossing materials are utilized in nearly regions of clamor control building to decrease sound weight levels. To utilize them successfully, it is important to:

- $\quad$ Recognize the significant physical characteristics and parameters that reason a material to assimilate sound.

- Give a portrayal of the acoustical presentation of sound safeguards used to perform explicit clamor control capacities

- $\quad$ Create test systems to gauge the acoustical parameters important to quantify the acoustical parameters of sound retaining materials and the acoustical exhibition of sound safeguards.

- Presentation of sound retaining materials in commotion control fenced in areas, spreads and wrappings to diminish reverberant develop and thus increment inclusion misfortune

- Presentation of sound engrossing materials onto surfaces of rooms to control reflected sound.

\subsection{Sound Absorption}

- Absorptive materials are utilized to control airborne sound by lessening reflections (froths, mineral fleece).

- These are connected in the traveler compartment and progressively in the motor cove (under the hood, on firewall, on under-plate).

- For an absorptive limit, the retention coefficient is characterized as the proportion of consumed force to occurrence power.

\subsection{Porous Absorptive Materials}

Permeable retaining materials are generally over $90 \%$ air The little pores lead to scattering of the sound proliferating through them.

At high frequencies a permeable material has an acoustic impedance like that of air. Most occurrence vitality enters the permeable material and is consumed there.

At low frequencies, a layer of permeable material acts acoustically like solidness. This prompts huge reflection and little retention. 


\subsection{Mechanism of Sound Absorption in Fibrous Materials}

Warm Misfortunes the swaying weight acting at the material makes the air atoms waver in the pores at the recurrence of the excitation. This outcomes in sound vitality being disseminated as warmth because of grating misfortunes. This system is significant at high frequencies.

Energy Misfortunes Alters in stream course just as extensions and compressions of the move through the unpredictable pores offers ascend to lost force toward wave spread. This system is significant at high frequencies.

\subsection{Reverberation:}

At the point when the amplifier is killed, it sets aside a limited length of effort for the soundlevel in the space to rot to indistinctness. This delayed consequence of the sound in a room, after the excitation sign has been evacuated, is Reverberation and it has a significant bearing on the acoustic nature of the room.

An ensemble symphony recorded in a huge anechoic chamber, with no room Reverberation, would yield an account of low quality for typical tuning in. This recording would be considerably more slender, flimsier, and less full than most open air accounts of music, which are noted for their evenness. Obviously, symphonic and other music expects Reverberation to accomplish a worthy sound quality. Also, numerous music also, discourse sounds require a room's reverberant help to sound characteristic, in light of the fact that we are acclimated with hearing them in reverberant situations. Once, Reverberation was viewed as the absolute most significant normal for an encased space for discourse or music. Today, Reverberation is viewed as one of a few significant and quantifiable parameters that characterize the sound nature of an acoustic space.

\section{OBSERVATION}

5.1 Daily Variation in Noise Level:

Daily Noise variation at CSIBER square:-

\begin{tabular}{|c|c|c|}
\hline \multicolumn{3}{|c|}{$\begin{array}{l}\text { Noise Level at CSIBER square for a week at 10.00A.M. }\left(1^{\text {st }}\right. \\
\text { October to } 7^{\text {th }} \text { October) }\end{array}$} \\
\hline Day & $L_{\text {eq. }} \cdot d B$ & Temperature in ${ }^{0} \mathrm{C}$ \\
\hline Monday & 78.5 & 30 \\
\hline Tuesday & 78.1 & 31 \\
\hline Wednesday & 76.6 & 33 \\
\hline Thursday & 79.3 & 30 \\
\hline Friday & 77.4 & 34 \\
\hline Saturday & 75.2 & 29 \\
\hline Sunday & 73.1 & 30 \\
\hline
\end{tabular}

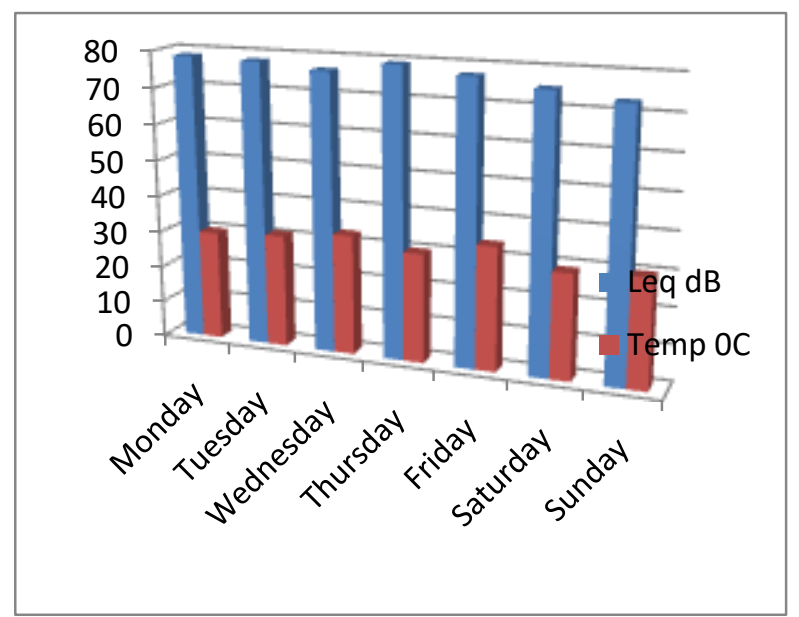

Daily variation in Noise level at CSIBER Square

Daily Noise variation at Dabholkar Corner:-

\begin{tabular}{|c|c|c|}
\hline $\begin{array}{l}\text { Noise Level at Dabholkar Corner for a week at 10.00 A.M. } \\
\left(\mathbf{2 2}^{\text {nd }} \text { October to } \mathbf{2 8}^{\text {th }} \text { October) }\right.\end{array}$ \\
\hline Day & $\mathbf{L}_{\text {eq. }} \mathbf{d B}$ & Temperature in ${ }^{\mathbf{0}} \mathbf{C}$ \\
\hline Monday & 82.9 & 29 \\
\hline Tuesday & 83.2 & 31 \\
\hline Wednesday & 81.5 & 32 \\
\hline Thursday & 80.8 & 28 \\
\hline Friday & 82.7 & 33 \\
\hline Saturday & 80.4 & 30 \\
\hline Sunday & 81.1 & 35 \\
\hline
\end{tabular}

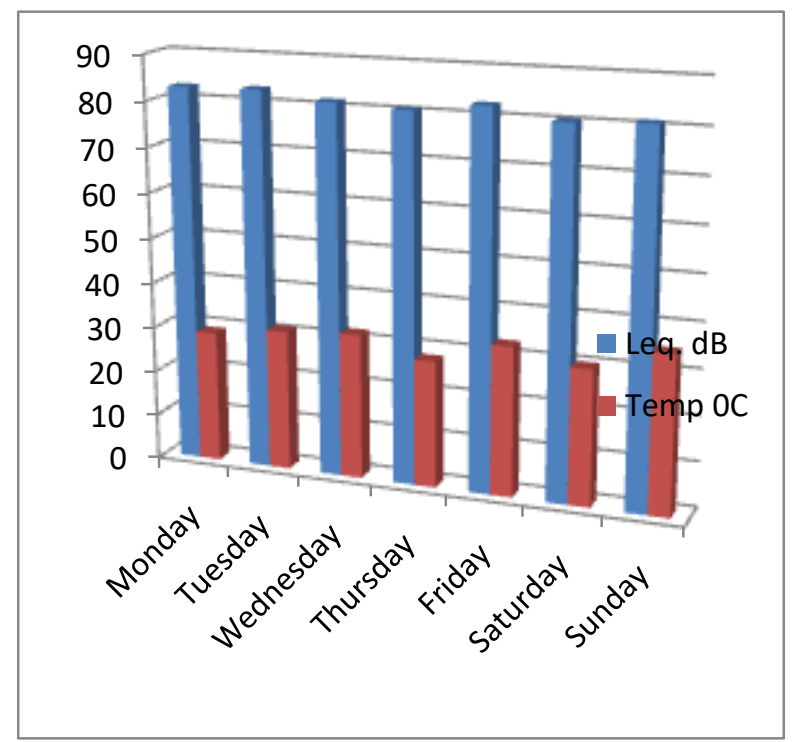

Daily variation in Noise level at Dabholkar Corner

\subsection{Hourly Variation in Noise Level:}

Maximum Noise Level for duration of 10 minutes duration and hourly temperature variation was recorded at CSIBER Square and Dabholkar Corner. The readings are as follows. 
Hourly Noise variation at CSIBER square:-

\begin{tabular}{|c|c|c|}
\hline \multicolumn{3}{|c|}{$\begin{array}{l}\text { Noise Level at CSIBER Square for a Day } \\
\left(26^{\text {th }} \text { Feb 2019) }\right.\end{array}$} \\
\hline Time & $L_{\max } \cdot d B$ & Temperature in ${ }^{0} \mathrm{C}$ \\
\hline 10 A.M & 82.9 & 29 \\
\hline 11 A.M & 83.5 & 31 \\
\hline 12 P.M & 81.7 & 32 \\
\hline 1 P.M & 78.9 & 33 \\
\hline 2 P.M & 78.5 & 34 \\
\hline 3 P.M & 79.7 & 32 \\
\hline 4 P.M & 81.1 & 31 \\
\hline 5 P.M & 82.7 & 29 \\
\hline 6 P.M & 84.0 & 28 \\
\hline
\end{tabular}

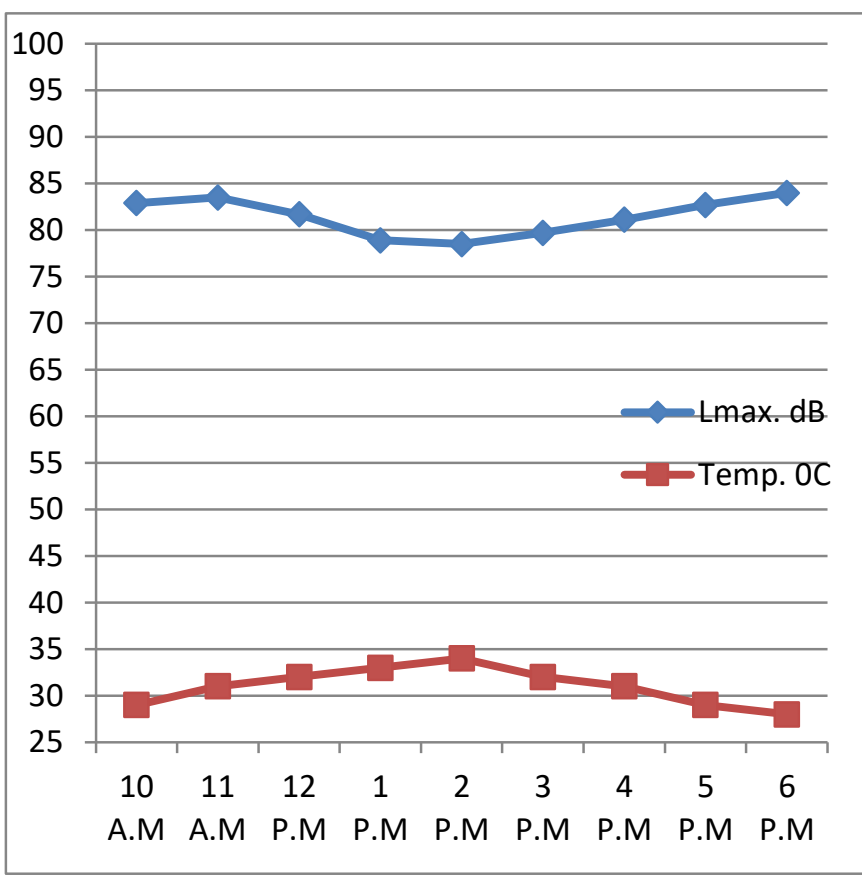

Hourly variation in Noise level at CSIBER Square

Maximum noise was recorded at 11 A.M and 6 P.M and minimum noise level was recorded at 2 P.M, when temperature was at peak.

Hourly Noise variation at Dabholkar Corner:-

\begin{tabular}{|c|c|c|}
\hline \multicolumn{3}{|c|}{$\begin{array}{l}\text { Noise Level at Dabholkar Corner for a Day } \\
\left(1^{\text {th }} \text { May 2019) }\right.\end{array}$} \\
\hline Time & $L_{\max } \cdot \mathbf{d B}$ & Temperature in ${ }^{0} \mathrm{C}$ \\
\hline 10 A.M & 85.9 & 30 \\
\hline 11 A.M & 86.3 & 30 \\
\hline 12 P.M & 85.4 & 32 \\
\hline 1 P.M & 83.1 & 34 \\
\hline 2 P.M & 82.7 & 33 \\
\hline 3 P.M & 81.2 & 34 \\
\hline 4 P.M & 83.8 & 31 \\
\hline 5 P.M & 86.8 & 30 \\
\hline 6 P.M & 88.5 & 29 \\
\hline
\end{tabular}

Dabholkar corner always faces high level of Noise. This is one of main point with maximum rush in Kolhapur city. Central Bus stand is situated near to Dabholkar corner, so movement of buses, small vehicles, honking etc. Hourly representation at Dabholkar corner is shown in graph below.

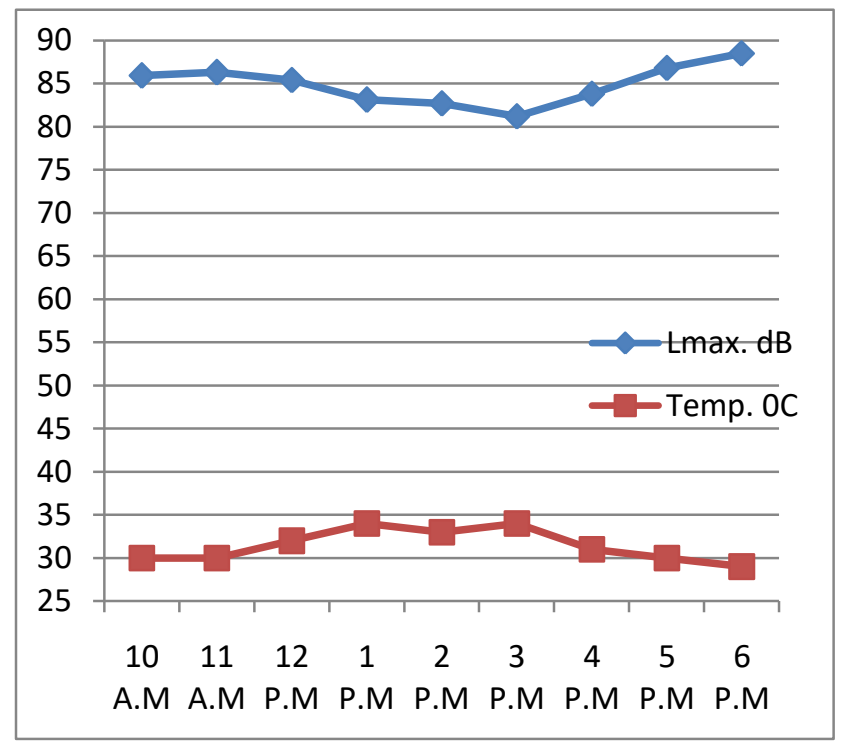

Hourly variation in Noise level at Dabholkar Corner

\subsection{Noise Level survey at Kolhapur Airport:}

Kolhapur airport is situated at Ujlaiwdi, $9 \mathrm{Km}$ South- East from Kolhapur city. The present Kolhapur Airport began operations in the year 1987 and was leased by the Maharashtra Industrial Development Corporation (MIDC) from Airports Authority of India (AAI) on 16 April 1997. The rent lapsed in February 2012 and the MIDC mentioned the State government in May 2012 to be soothed of the obligation of dealing with the air terminal. The Maharashtra Government at that point gave over the airplane terminal to the AAI in August 2013.Kolhapur airport is under development phase. Survey was conducted on $4^{\text {th }}$ March 2019. At that time two flights were in operation for Hyderabad and Benglore. One more flight to Tirupati has started from $12^{\text {th }}$ may 2019 . So the impact of noise level from Kolhapur airport should be considered.

Survey results from Airport are as follows:

Noise Level report at Kolhapur Airport:-

\begin{tabular}{|c|c|l|c|}
\hline \multicolumn{4}{|c|}{ Noise Level at Kolhapur Airport } \\
\hline Sr. No. & Location & Source of Sound & $\mathbf{L}_{\mathrm{eq}} \mathbf{d B}$ \\
\hline 1 & Entrance & Passengers and vehicles & 67.4 \\
\hline 2 & Check In area & $\begin{array}{l}\text { Passengers, X Ray } \\
\text { machine, AC }\end{array}$ & 71.5 \\
\hline 3 & $\begin{array}{c}\text { Security Hold } \\
\text { area }\end{array}$ & $\begin{array}{l}\text { Passengers, Security } \\
\text { Equipment's }\end{array}$ & 80.9 \\
\hline 4 & Arrival & Passengers & 70.7 \\
\hline 5 & Runway Area & While Landing & 103.6 \\
\cline { 3 - 4 } & While Take Off & 102.8 \\
\hline 6 & CNS office & Office staff & 57.4 \\
\hline 7 & $\begin{array}{c}\text { CNS Equipment } \\
\text { room }\end{array}$ & Electronic Equipment & 72.3 \\
\hline 8 & APD office & AC, fan & 52.4 \\
\hline 9 & ATC Tower & $\begin{array}{l}\text { Electronic Equipment, } \\
\text { AC }\end{array}$ & 56.0 \\
\hline
\end{tabular}




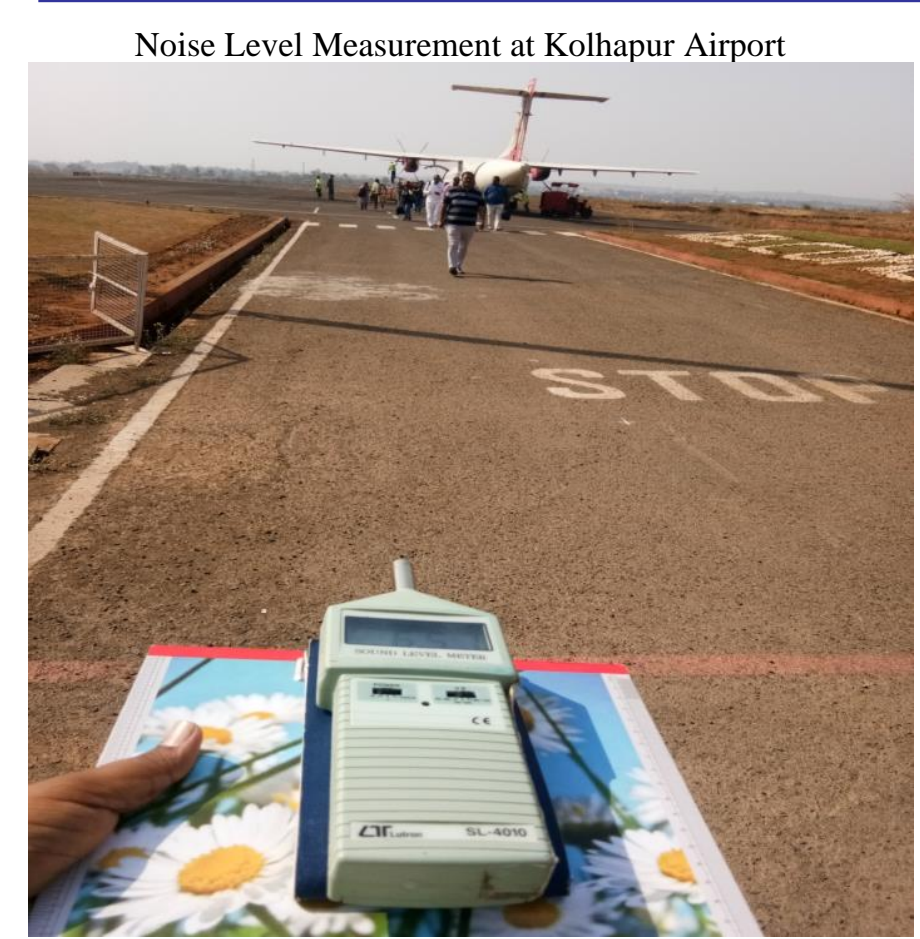

\section{TECHNICAL REMEDIES TO REDUCE NOISE LEVEL}

\subsection{Noise reduction}

It is frequently necessary to use techniques that lower the level of noise on the road side or at source. Assortments of techniques are accessible for commotion decrease however they can be fundamentally assembled as pursues: inactive and dynamic medium. Dynamic medium vary from aloof mediums in that it is important to apply outer vitality in the commotion decreasing procedure. The engrossing materials, in that capacity, are aloof mediums that lower clamor by scattering vitality and transforming it into warmth given by Environmental Protection Department Hong Kong (Anon. 2006a).

The methods utilized for clamor control can be extensively named:

- Control at source

- Control in the transmission way

- Utilizing defensive gear.

\subsection{Noise barrier}

Noise barriers are typically constructed of cast-in-place concrete or masonry block in certain areas, where space allows and where soil material is available, earth berms are constructed as noise barriers. The hindrances successfully diminish commotion levels, however regularly cause unfortunate optional effects, for example, blocked perspectives on houses, hindering the passage point for houses, frontal view, picturesque highlights, and diminished perceivability from the roadway, huge shadows cast over an occupant's front yard and lawn for expanded times of the day. Raising clamor hindrances to accomplish further commotion decrease regularly fuels these auxiliary effects (Anon. 2006c). Creative clamor hindrance structures and medications have been effectively executed in different nations for various years. These creative structures have permitted the development of a commotion divider as a customary divider. A portion of the imaginative materials and structures that have been explored and utilized in different wards incorporate straightforward boards, semi-translucent solid materials, acoustical medications, and extraordinarily planned top medicines, for example, bended or calculated tops, unpredictable top edges, or T-top medications. Huge numbers of these structures have their very own points of interest and hindrances (Anon. 2006c).

\subsection{Dhwani Balanigrahak Panel}

It is a Sanskrit name, Dhwani means sound and Balanigrahak means Strength Reducer. This panel helps to reduce noise level up to 6 to $8 \%$ in initial stages of testing in indoor condition.

\section{List of Materials used for panel:}

1. Wooden frame: $87 \mathrm{~cm} \mathrm{X} 170 \mathrm{~cm}$ rectangular in shape.

2. PVC Pipes: 2.5" placed horizontally, total 13 PVC pipes are used

3. Binding Wire: Used to bind PVC pipes with wooden frame.

4. Cardboard: To cover back side of the frame

\section{Procedure to assemble panel:}

1. PVC pipes are bounded with frame horizontally.

2. Holes are drilled horizontally in pipes at spacing $5 \mathrm{~cm}$ center to center.

3. Open ends of pipes are closed using thermocol

\section{Salient Features of Dhwani Balanigrahak Panel:}

1. Panels are completely made from scrap material so cost of panel is low.

2. As scrap material like PVC pipe is used, reuse of waste material is done.

3. It reduces near about 6 to $8 \%$ noise level in indoor testing.

4. As there is no machinery involved, maintenance cost of panel is negligible.

\section{Working Principle:}

1. When panel is kept between the source of noise and receiver the noise waves passes through holes drilled in PVC pipes.

2. As noise wave gets inside the pipes some waves gets reflected, some gets passed through panels to receiver end and some gets trapped inside the voids of pipes.

3. These trapped waves get enough space to travel and gets dissipated inside the pores.

4. The efficiency of the panel can be increased by increasing the number of voids and area of the panel.

Barrier

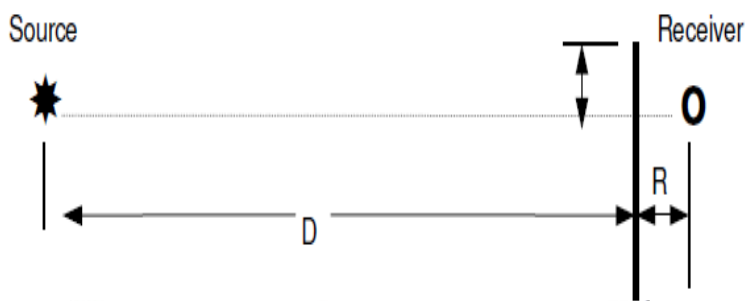


Observations of Dhwani Balanigrahak inside the laboratory in initial stage:

For testing of panel inside laboratory a stationary source with increasing noise level was used and panel was placed between source and receiver which are $1.5 \mathrm{~m}$ apart from each other. The observations were as follows:

\subsubsection{Dhwani Balanigrahak Panel with holes (No filler material)}

Test results of Dhwani Balanigrahak panel:-

\begin{tabular}{|c|c|c|c|c|}
\hline $\begin{array}{c}\text { Test } \\
\text { No. }\end{array}$ & $\begin{array}{c}\mathbf{L}_{\text {source }} \\
\mathbf{d B}\end{array}$ & $\begin{array}{c}\mathbf{L}_{\text {receiver }} \\
\mathbf{d B}\end{array}$ & $\begin{array}{c}\text { Reduction } \\
\mathbf{d B} \\
\mathbf{L}_{\text {source }} \\
\mathbf{L}_{\text {receiver }}\end{array}$ & $\begin{array}{c}\text { Percentage } \\
\text { reduction }\end{array}$ \\
\hline 1 & 72.6 & 67.1 & 5.5 & 7.57 \\
\hline 2 & 74.4 & 69.3 & 5.1 & 6.85 \\
\hline 3 & 76.8 & 71.5 & 5.3 & 6.90 \\
\hline 4 & 80.5 & 73.6 & 6.9 & 8.57 \\
\hline
\end{tabular}

Above test was conducted in laboratory at room temperature. Test result shows that Dhwani Balanigrahak reduces noise level by near about $5.7 \mathrm{~dB}$. This value is the average of the above four test results.

This shows that Dhwani Balanigrahak cause $6 \%$ to $8 \%$ noise reduction which is more pleasant to hearing.

Graphical representation of test data is as follows:

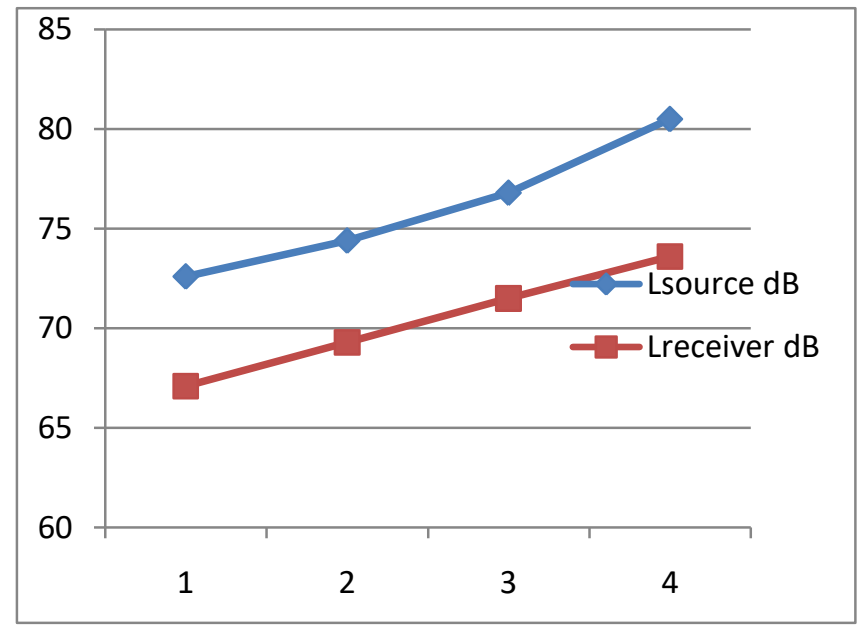

Test data representation for Dhwani Balanigrahak panel.

\subsubsection{Dhwani Balanigrahak Panel with horizontal sholes and filler material Foam:}

Test results of Dhwani Balanigrahak panel:-

\begin{tabular}{|c|c|c|c|c|}
\hline $\begin{array}{c}\text { Test } \\
\text { No. }\end{array}$ & $\begin{array}{c}\mathbf{L}_{\text {source }} \\
\mathbf{d B}\end{array}$ & $\begin{array}{c}\mathbf{L}_{\text {receiver }} \\
\mathbf{d B}\end{array}$ & $\begin{array}{c}\text { Reduction } \\
\mathbf{d B} \\
\mathbf{L}_{\text {source }} \\
\mathbf{L}_{\text {receiver }}\end{array}$ & $\begin{array}{c}\text { Percentage } \\
\text { reduction }\end{array}$ \\
\hline 1 & 63.5 & 52.1 & 11.4 & 17.95 \\
\hline 2 & 65.3 & 55.7 & 9.6 & 14.70 \\
\hline 3 & 67.8 & 56.9 & 10.9 & 16.07 \\
\hline 4 & 70.1 & 59.5 & 10.6 & 15.12 \\
\hline
\end{tabular}

Above test was conducted in laboratory at room temperature. Test result shows that Dhwani Balanigrahak reduces noise level by near about $10.62 \mathrm{~dB}$. This value is the average of the above four test results.

This shows that Dhwani Balanigrahak cause $16 \%$ to $18 \%$ noise reduction which is more pleasant to hearing.

Graphical representation of test data is as follows:

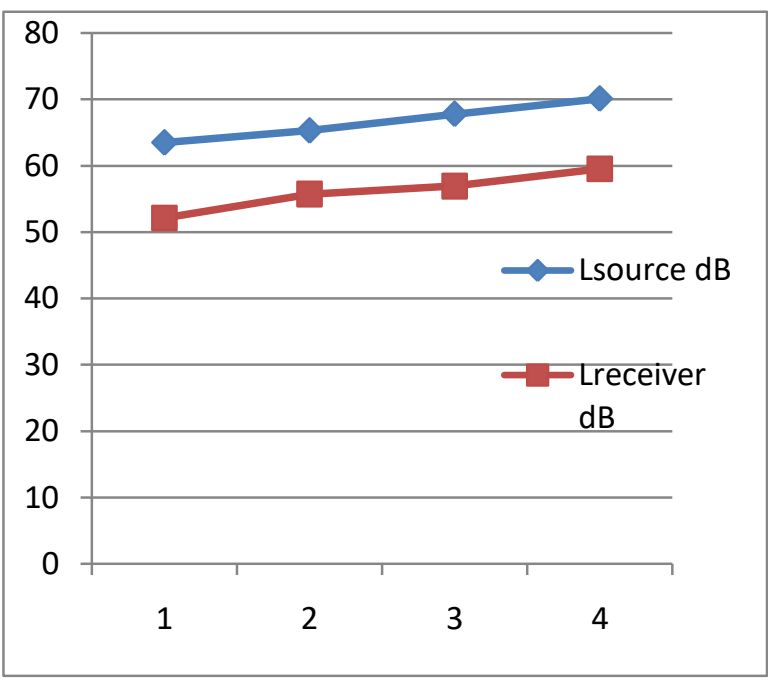

\subsubsection{Dhwani Balanigrahak Panel with horizontal strips and filler material Foam:}

Test results of Dhwani Balanigrahak panel:-

\begin{tabular}{|c|c|c|c|c|}
\hline $\begin{array}{c}\text { Test } \\
\text { No. }\end{array}$ & $\begin{array}{c}\mathbf{L}_{\text {source }} \\
\mathbf{d B}\end{array}$ & $\begin{array}{c}\mathbf{L}_{\text {receiver }} \\
\mathbf{d B}\end{array}$ & $\begin{array}{c}\text { Reduction } \\
\mathbf{d B} \\
\mathbf{L}_{\text {source }} \\
\mathbf{L}_{\text {receiver }}\end{array}$ & $\begin{array}{c}\text { Percentage } \\
\text { reduction }\end{array}$ \\
\hline 1 & 62.5 & 50.1 & 12.4 & 19.84 \\
\hline 2 & 64.3 & 51.7 & 12.6 & 19.59 \\
\hline 3 & 65.2 & 52.3 & 12.9 & 19.78 \\
\hline 4 & 66.8 & 55.4 & 11.4 & 17.06 \\
\hline
\end{tabular}

Above test was conducted in laboratory at room temperature. Test result shows that Dhwani Balanigrahak reduces noise level by near about $12.32 \mathrm{~dB}$. This value is the average of the above four test results.

This shows that Dhwani Balanigrahak cause $19 \%$ to $20 \%$ noise reduction which is more pleasant to hearing. 
Graphical representation of test data is as follows:

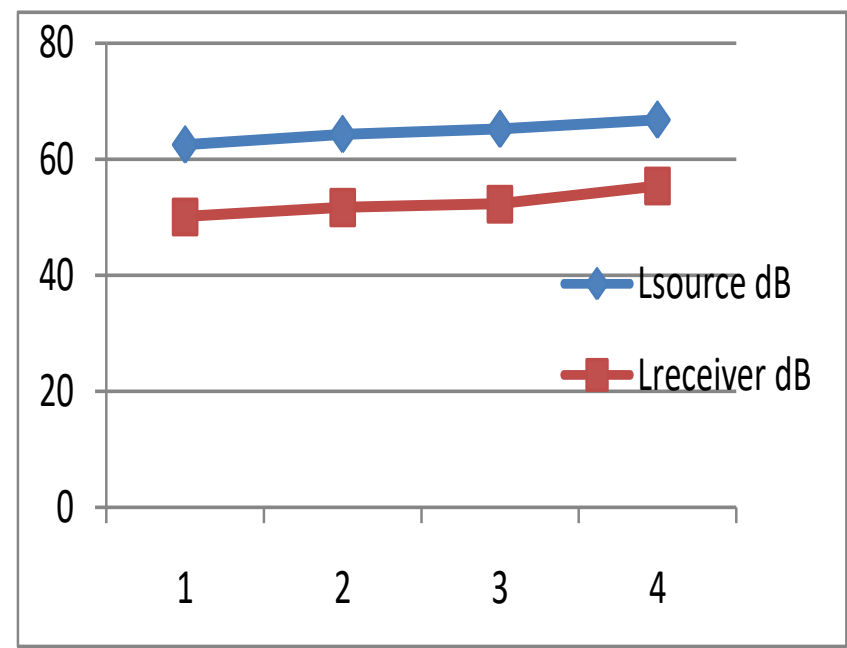

6.3.4 Dhwani Balanigrahak Panel with horizontal strips and filler material Foam and sponge:

Test results of Dhwani Balanigrahak panel:-

\begin{tabular}{|c|c|c|c|c|}
\hline $\begin{array}{c}\text { Test } \\
\text { No. }\end{array}$ & $\begin{array}{c}\mathbf{L}_{\text {source }} \mathbf{d B} \\
\mathbf{d B}\end{array}$ & $\begin{array}{c}\mathbf{L}_{\text {receiver }} \\
\mathbf{d B}\end{array}$ & $\begin{array}{c}\text { Reduction } \\
\mathbf{d B} \\
\mathbf{L}_{\text {source }} \\
\mathbf{L}_{\text {receiver }}\end{array}$ & $\begin{array}{c}\text { Percentage } \\
\text { reduction }\end{array}$ \\
\hline 2 & 65.9 & 52.7 & 13.2 & 20.03 \\
\hline 3 & 63.8 & 52.1 & 11.7 & 18.33 \\
\hline 4 & 75.4 & 63.2 & 12.2 & 16.18 \\
\hline
\end{tabular}

Above test was conducted in laboratory at room temperature. Test result shows that Dhwani Balanigrahak reduces noise level by near about $12.50 \mathrm{~dB}$. This value is the average of the above four test results.

This shows that Dhwani Balanigrahak cause $18 \%$ to $21 \%$ noise reduction which is more pleasant to hearing.

Graphical representation of test data is as follows:

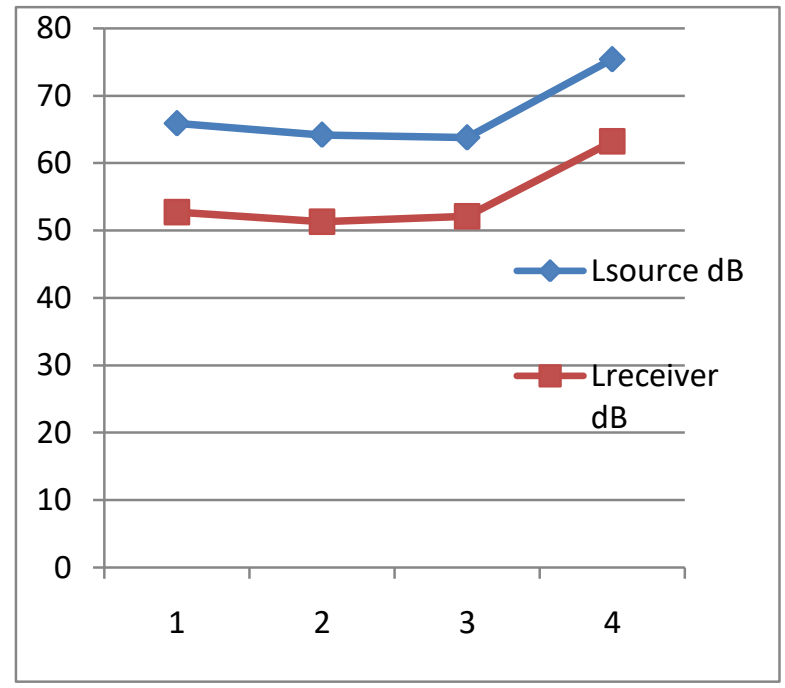

Dhwani Balanigrahak Panel with holes (No filler material)

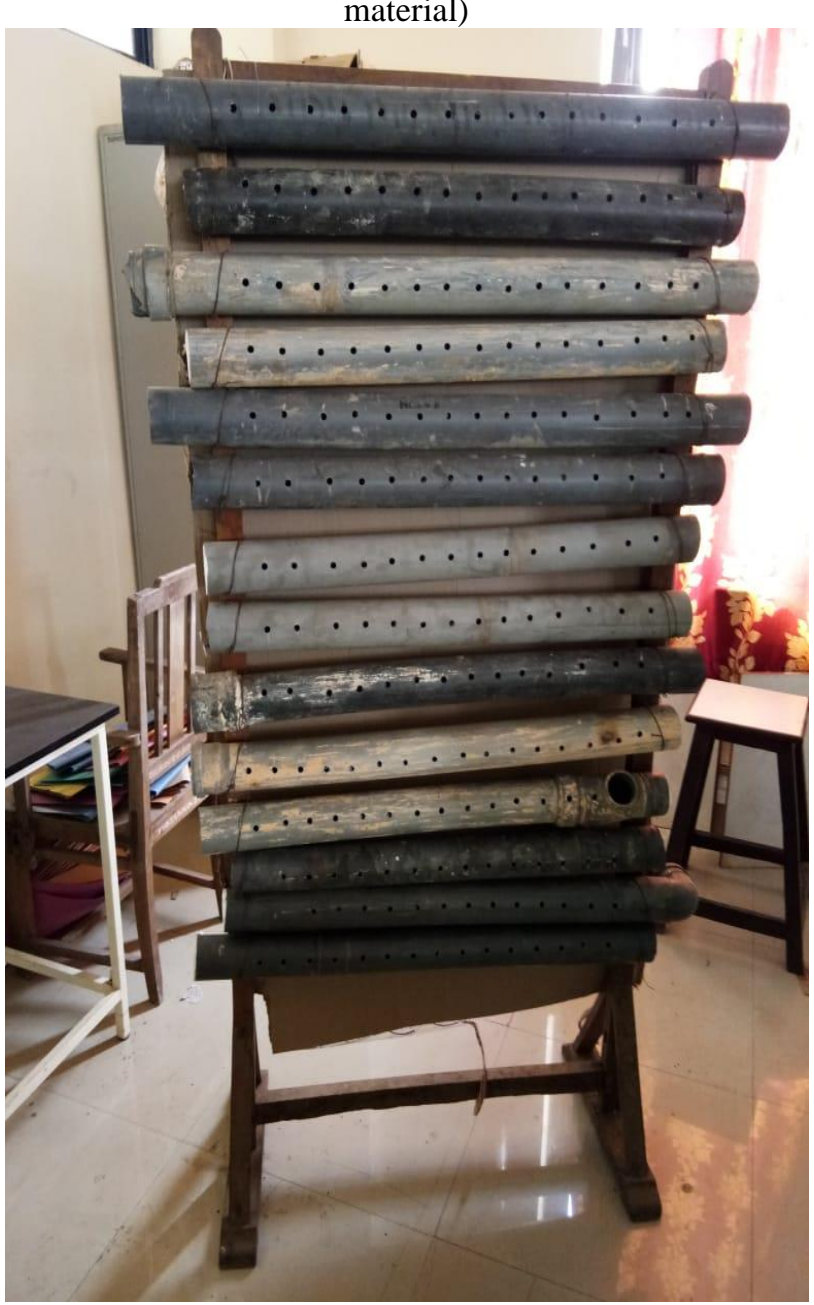

Dhwani Balanigrahak Panel with horizontal sholes and filler material

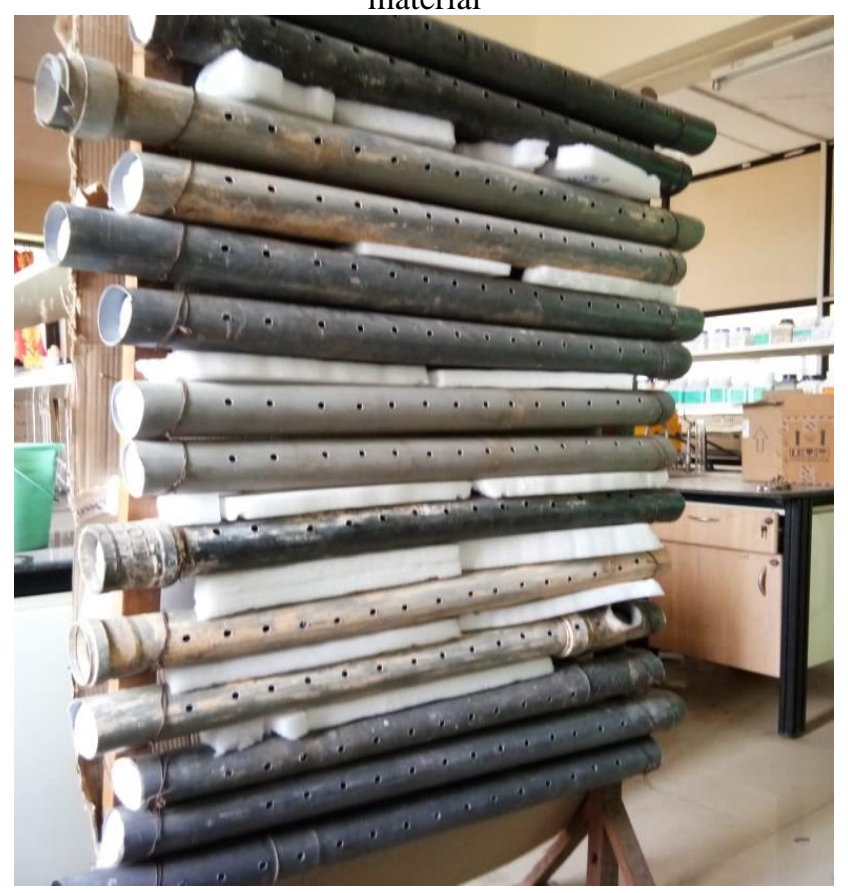

Dhwani Balanigrahak Panel with horizontal strips and filler material Foam and sponge 


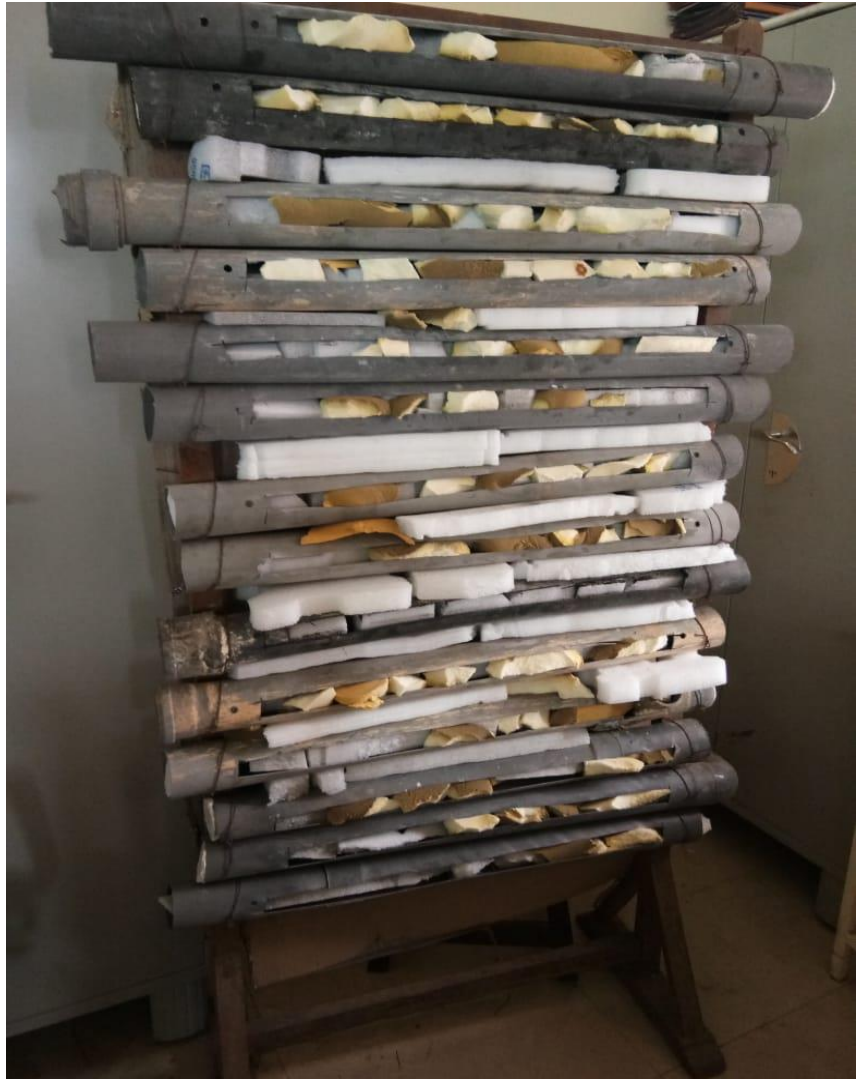

\section{CONCLUSION}

From the above study following conclusions can be made:

1) Noise Levels at CSIBER and Dabholkar Corner are more than the limits prescribed by the CPCB.

2) Dabholkar corner has more rush and vehicular movement at the same time it has less vegetation and it is fully surrounded by buildings, therefore Noise level at Dabholkar corner is more than CSIBER square.

3) Both the places require protective majors to reduce the noise level.

4) CSIBER square showed reduction in noise on Sunday due to holiday where as Dabholkar Corner has constant Noise level throughout the week.

5) In hourly variation both places showed reduced level of noise at afternoon. Allthough there is no major relation between temperature and noise level but still it can be concluded that increased temperature reduces the number of bikers and noise gets reduced to some extent in summer season at least.

6) Both places require vegetation, use of barrier and limitation on honking etc. to reduce noise level.

7) Noise level readings are within the limits as specified by IS: 4954- 1968 recommendations for Noise abatement in town planning.

8) Airport is located at $9 \mathrm{Km}$ away from the city but still some noise can be heard during the airplane activity. Therefore majors should be taken by considering the future growth of Kolhapur airport and more number of flights.

9) The 'Dhwani Balanigrahak panel (Noise Reducing panel) with holes and no filler, designed during this project reduces noise level by near about $6 \mathrm{~dB}$ in laboratory.

10) The 'Dhwani Balanigrahak panel (Noise Reducing panel) with horizontal strips and foam as filler, designed during this project reduces noise level by near about 11 $\mathrm{dB}$ in laboratory.

11) The 'Dhwani Balanigrahak panel (Noise Reducing panel) with horizontal strips and foam plus sponge as filler, designed during this project reduces noise level by near about $13 \mathrm{~dB}$ in laboratory, this will definitely reduce outdoor noise level and is the best reuse method for waste material.

12) The 'Dhwani Balanigrahak panel (Noise Reducing panel) with horizontal strips and foam plus sponge as filler, designed during this project has absorption coefficient of 0.22 .

\section{REFERENCES}

[1] Balashanmugam, P, Ramanathan, AR, Nehrukumar, V, Balasubramaniyan, V 2013 'Assessment of Noise Pollution in Chidambaram Town', International Journal of Research in Engineering and Technology, vol. 2, issue. 10, pp. 85 -93

[2] Can, A, Leclercq, L, Lelong, J \&Botteldooren, D 2010 'Traffic noise spectrum analysis: dynamic modelling vs. Experimental observations' Journal of applied acoustics, vol.71, issue 8, pp. 7645770

[3] Dasarathy, AK \&Thandavamoorthy, TS 2013a 'Noise Pollution in Chennai - A Case Study', Asia Pacific Journal of Research, vol. 1, issue. XI, pp. 143-148

[4] Dasarathy, AK \&Thandavamoorthy, TS 2013b 'Attenuation of noise using barrier in the form of enclosures', Journal of Applied Research, vol. 3, issue. 8, pp. 83-89

[5] Gilchrist, A, Allouche, EN \& Cowan, N 2003 'Prediction and mitigation of construction noise in an urban environment', Canadian Journal of Civil Engineering, vol. 30, pp. 659-672

[6] Mangalekar, SB, Jadhav, AS \& Raut, PD 2012 'Study of Noise Pollution in Kolhapur City, Maharashtra, India', Universal Journal of Environmental Research and Technology, vol. 2, issue. 1, pp. 6569

[7] Thangadurai, N, Venkateswaran, P \&Jeevanraj, S 2005 'Evaluation and analysis of noise quality of Ambur, TamilNadu, India' Journal of Environmental Sci and Engg, vol. 47, pp. 7-12

[8] TirtharajSen, PijushKantiBhattacharjee, Debamalya Banerjee \&Bijan Sarkar, 2010 'Study and Comparison of the Noise Dose on Workers in a Small Scale Industry in West Bengal, India', International Journal of Environmental Science and Development, vol.1, no. 4 , pp. $364-370$

[9] TurgutÖztürk, Zübeyde ÖZTÜRK \&Metehan ÇALIS 2012 'A case study on acoustic performance and Construction costs of noise barriers', Scientific Research and Essays, vol. 7, issue. 50, pp. 42134229

[10] VahidehAbolhasannejad, Mohammad Reza Monazzam\&NarjesMoasheri 2013 'Comparison of Noise Sensitivity and Annoyance Among the Residents of Birjand Old and New Urban Districts', Current World Environment, vol. 8(1), pp. 29-36

[11] Vidyasagar, T \& Rao, GN 2006 'Noise Pollution Levels in Visakhapatnam City (India)', Journal of Environmental Science and Engineering, vol. 48, no. 2, pp. 139-142

[12] Wendy, L, Martinez \& Angel R. Martinez 2005 'Exploratory Dato Analysis with MATLAB' Chapman \& Hall/CRC Press, London SW15 $2 \mathrm{NU}$

[13] Yang Fan, BaoZhiyi, Zhu Zhujun\& Liu Jiani 2010 'The investigation of noise attenuation by plants and corresponding noise reduction', Journal of Environmental Health, vol. 72, pp.8-12

[14] Web reference

[15] Annual Report 2005-2006 to combat noise pollution Activities of the West Bengal Pollution Control Board (WBPCB) www.wbpcb.gov.in/html/ annualreps/ar0607/ part1.pdf

[16] Anon. 2012 'Report on Noise and Vibrations' Indian Institute of Technology 
pptpresentation.http://www.iitro.in/publications/ppt presentations/html

[17] Anon. 2000 'Transit noise and vibrations assessment' Inc. Publications United States, chapter 12,pp. 12-1 to 12-12, www.fta.dot.gov/documents/FTA_Noise_and_Vibration Manual.pdf

[18] Anon. 2000 'The Ambient Air Quality Noise Standards in Respect of Noise as per GOI, MoEF Notification Environment (Protection) Act 1986 as amended in 2000' CPCB Chennai, www.envfor.nic.in/legis/noise/noise.html

[19] Anon. 2001 'Environmental health criteria of noise' World Health Organisation, (WHO) Occupational and community noise, Fact sheet 258, Geneva, www.who.int/quantifying_ ehimpacts/publications/en/ebd9.pdf

[20] Anon. 2006a 'Plan to tackle road traffic noise in Hong Kong' A Draft Comprehensive Plan Prepared by Environmental Protection Department, Hong Kong, www.epd.gov.hk/epd/ english/environmentinhk/noise/.../LNRS-final.pdf

[21] Anon. 2006b 'Mitigation measures against road traffic noise in selected places' Prepared by Jackie WU Research and Library Services Division Legislative Council Secretariat, Hong Kong, www.epd.gov.hk/epd/english/environmentinhk/noise/.../LNRSfinal.pdf

[22] Anon. 2006c 'Evaluation of benefits and opportunities for innovative noise barrier design' A Comprehensive plan prepared by Arizona Department of Transportation [ADOT].

[23] Anon. 2010a 'Understanding the most common sources of noise in the city' New York City Department of Environmental Protection Bureau of Environmental Compliance 59-17Junction Blvd, 11th Fl, Flushing, NY, www.nyc.gov/html/dep/pdf/noise_code_guide.pdf

[24] Anon. 2010b 'Good Practice Guide on Noise Exposure and Potential Health Effects' European Environment Agency - 36, pp ISBN 97892-9213-140-1 doi:10.2800/54080

\section{PUBLICATIONS}

International Journal

1. Dasarathy, AK \&Thandavamoorthy, TS 2014 'Noise Reduction Using Concrete Barriers: A Case Study', International Journal Earth Sciences and Engineering, vol. 7,no. 4, pp. 1449-1452

2. Dasarathy, AK \&Thandavamoorthy, TS 2014 'Noise reduction due to an enclosure constructed by fly ash bricks', International Journal Applied Environmental Sciences,vol. 9, no. 4, pp. 1749-1757

3. Dasarathy, AK \&Thandavamoorthy, TS 2014 'Construction noise pollution and itsattenuation', International Journal of Earth Sciences and Engineering, vol. 7, no. 5, pp.1458-1462 